\title{
Pattern Classification of Memorization of Key Words in Implementation Phase of Intellectual-Property Education
}

\author{
Hiroshi Murai
}

\begin{abstract}
This study is about Learning Support using classification of learners according to their type of memorization of key words in the implementation phase of intellectual-property (IP) education. In the implementation phase of IP education, learners start with an acquirement of knowledge such as the definition of legal terms or the purpose of the law and legal system. Therefore, accurate memorization of keywords is required. In this paper, we classify the type of memorization by the results of examination in the real class, and we utilize the results for learning support by individual tutoring.
\end{abstract}

Index Terms - Intellectual Property Education, Learning Support, Pattern Classification.

\section{INTRODUCTION}

Since an oral examination in law is proceeded on legal qualifying examination to know whether the learner understands IP law or not, we need individual guidance to a learner. But the individual guidance puts a large burden on a teacher. Therefore, we have attempted to support intellectual-property (IP) education automatically in the past researches [1]-[5]. The proposed system that has recommended learning contents suitable for a one-on-one instruction. The recommendation has been decided by the estimation of type of the learners' comprehension.

In the reference [5], we examined the similarity of the type of learners' comprehension classified by SOM classifier. The results show that some classes are similar to each other because of the characteristics of the learners' comprehension. Therefore, we need to divide the different types of learners classify in the same unit when we recommend the learning contents suitable to the learner. But, increasing of the variation of the type of learners' comprehension causes a large burden on the teacher to prepare for the individual guidance. Therefore, it is important that we should not increase the class by making rules of revising misclassification based on the teaching knowledge.

On the other hand, we proposed a pattern classification method which integrates the advantages of both the neural network and knowledge-based system on the remote sensing image analysis [7]. We found that the misclassification can be revised more easily because of introducing the geographical knowledge into the system [8].

In this paper, we apply the one-on-one instruction function

Hiroshi Murai is with the Yamaguchi University, Yamaguchi, 753-8541 Japan based on learners' comprehension after revised misclassification by teaching knowledge.

\section{METHODOLOGY}

\section{A. Processing Flow of Proposed System}

The proposed system consists of four functions:

1) execution of online test using categorized questions

2) measurement of four learner's academic skills

3)classification of learner's comprehension type to recommend suitable learning contents for the learner.

4) one-on-one instruction

We defined six types of learners' comprehension based on their academic skills, namely, Master, Adept, Careless, Neophyte and Others illustrated in Table I. We can estimate the type of learners' comprehension based on their academic skills calculated by the measurement function. In addition, academic. TABLE I.

CATEGORIZATION OF LEARNER'S COMPREHENSION AND EXPLANATION OF CATEGORY

\begin{tabular}{|c|c|c|}
\hline No. & Category & Estimation Rules / Explanation of Category \\
\hline \multirow{2}{*}{1} & \multirow{2}{*}{ Master } & $\begin{array}{l}\text { All skills were } 0.8 \text { and over, or average of correct } \\
\text { answer ratio of all questions is } 0.8 \text { and over. }\end{array}$ \\
\hline & & Learner who achieved excellent results. \\
\hline \multirow{2}{*}{2} & \multirow{2}{*}{ Adept } & $\begin{array}{l}\text { Lowest skill was Thinking among three skills, such } \\
\text { as Memory, Judgement, and Thinking. }\end{array}$ \\
\hline & & $\begin{array}{l}\text { Learner who acquired basic knowledge but was not } \\
\text { good at the thinking. }\end{array}$ \\
\hline \multirow{2}{*}{3} & \multirow{2}{*}{ Careless } & $\begin{array}{l}\text { Lowest skill was Judgement among three skills, such } \\
\text { as Memory, Judgement, and Thinking. }\end{array}$ \\
\hline & & $\begin{array}{l}\text { Learner who acquired basic knowledge but was not } \\
\text { good at the judgement. }\end{array}$ \\
\hline \multirow[b]{2}{*}{4} & \multirow[b]{2}{*}{ Apprentice } & All skills were under 0.6 . \\
\hline & & $\begin{array}{l}\text { Learner who memorized the meaning of the legal } \\
\text { terms. }\end{array}$ \\
\hline \multirow{2}{*}{5} & \multirow{2}{*}{ Neophyte } & $\begin{array}{l}\text { Correct answer ratio of questions of legal terms was } \\
\text { under } 0.6 \text {. }\end{array}$ \\
\hline & & Learner who started learning. \\
\hline 6 & Others & \\
\hline
\end{tabular}

skills are measured for labeling the training data. After classification by unsupervised method (SOM), we examine similarity of competitive units. Finally, the proposed system send the learner an individual guidance for automatic one-on-one instruction. 


\section{B. Categorized questions}

In this paper, we classify the questions to six categories with learning objectives corresponding to the learning steps on the IP education illustrated in Table II.

TABLE II: THE CATEGORIZED QUESTIONS

\begin{tabular}{|c|c|c|}
\hline Category Name & Learning Step & Learning Objectives \\
\hline $\begin{array}{l}\text { 1) Questions on } \\
\text { Legal Terms } \\
\text { 2) Questions on } \\
\text { Purposes }\end{array}$ & $\begin{array}{l}\text { Memorize } \\
\text { Definitions of Legal } \\
\text { Terms and Purposes }\end{array}$ & $\begin{array}{l}\text { A) Memorize the meaning of } \\
\text { legal terms. } \\
\text { B) Distinction of the similar } \\
\text { legal terms. }\end{array}$ \\
\hline $\begin{array}{l}\text { 3) Questions on } \\
\text { Requirements }\end{array}$ & $\begin{array}{l}\text { Understand Law } \\
\text { System: } \\
\text { Proceedings, } \\
\text { Requirements and } \\
\text { Effects, }\end{array}$ & $\begin{array}{l}\text { A) Reproduction of the key } \\
\text { phrase about purpose of the } \\
\text { law system exactly. } \\
\text { B) Enumeration of important } \\
\text { requirements exactly. }\end{array}$ \\
\hline $\begin{array}{l}\text { 4) Questions on } \\
\text { Applications } \\
\text { 5) Questions on } \\
\text { Proceedings }\end{array}$ & $\begin{array}{l}\text { Apply Basic } \\
\text { Knowledge to Cases }\end{array}$ & $\begin{array}{l}\text { A) Explanation of the legal terms } \\
\text { that are not defined by the text } \\
\text { exactly. } \\
\text { B) Explanation of important } \\
\text { proceedings without losing } \\
\text { requirements or key phrases. }\end{array}$ \\
\hline $\begin{array}{l}\text { 6) Questions of } \\
\text { Justifications }\end{array}$ & Describe Reasons & $\begin{array}{l}\text { A) Description using key } \\
\text { phrases of important text and } \\
\text { commonly accepted view. }\end{array}$ \\
\hline
\end{tabular}

\section{Type of Learners' Comprehension}

Fig. 1 illustrates two typical learners' mistakes, Sample A is a mistake when they memorize the important words. The question is formed in Fill-in-Blanks. The average of correct answer ratio of this question is about $90.7 \%$. The average for each choice is follows. Most of the learners answered correctly. The choice of

\begin{tabular}{|c|c|}
\hline$A$ & $\begin{array}{l}\text { Question } \\
\text { Fill in the following blanks. } \\
\text { A compilation that, by reason of the [ selection or arrangement ] of its } \\
\text { [ contents ], constitutes an intellectual creation, is protected as a work. } \\
\text { Answers } \\
\text { a) selection / data } \\
\text { b) arrangement / contents } \\
\text { c) selection or arrangement / contents } \\
\text { d) arrangement / data }\end{array}$ \\
\hline B & $\begin{array}{l}\text { Question } \\
\text { Compare the following descriptions that relates to the case where you } \\
\text { received a warning of infringing someone's patent right, then choose the } \\
\text { most appropriate one. } \\
\text { Answers } \\
\text { a) Where the patentee doesn't show a patent registration that an } \\
\text { examiner of the Patent Office prepared, the patentee cannot } \\
\text { exercise the patent rights. } \\
\text { b) Where a patented invention has not been used for three consecutive } \\
\text { years or longer by the patentee, any person may file a request for a } \\
\text { trial for rescission of such patent. } \\
\text { c) Where a request for a trial for patent invalidation on the ground of } \\
\text { the joint application violation may be filed by only the person who } \\
\text { has the right to obtain a patent. }\end{array}$ \\
\hline
\end{tabular}

Fig. 1. Sample of Two Typical Learners' Mistakes

b) shows that about $6 \%$ of the learner remembered the keyword "contents", but didn't remember "selection".

Sample B shows the mistakes when the learners apply basic knowledge to solve a case problem. The average of correct answer ratio of the case problems is lower than that one of definition of legal terms, because they are more difficult. In this sample, both a) and b) are confusing Questions to confirm whether the learners understood the legal knowledge precisely or not. The average for each choice is distributed equally. Maybe, it was a difficult question for the learners.

TABLE III. SUMMARY OF ONLINE COURSE

\begin{tabular}{ll}
\hline \hline & Explanation \\
\hline Course Name & Local contents and Intellectual Property Management \\
\hline Learning Style & on-demand e-Learning \\
\hline No. of Learners & 199 \\
\hline No. of Questions & 30 \\
& $\begin{array}{l}\text { Terms: 3, Purposes: 6, Requirements: 4, Applications: 8, } \\
\\
\end{array}$ Proceedings: 7, Descriptions: 2 \\
\hline \hline
\end{tabular}

The proposed system was implemented in an introductory course of on-demand e-Learning at five universities in Japan. The summary of the online course is illustrated in Table III. The number of learners is 199 and that of questions is 30 [3], [7]. Questions on "Legal Terms" are useful to memorize definition of legal terms at the first learning step. Questions on "Purposes" and "Requirements" ask knowledge whether the learner can use the important key phrases and enumerate the important requirements exactly. We made similar choices in the phase of making questions in order to ask whether the learner would be able to memorize or judge correct answers.

TABLE IV SIMILARITY $S_{I J}$ OF EACH TYPES OF LEARNERS' COMPREHENSION

\begin{tabular}{r|r|r|r|r|r|r}
\multirow{2}{*}{$\begin{array}{l}\text { Classification } \\
\text { Results of Type } j\end{array}$} & \multicolumn{7}{|c}{ Training Data of Type $i$} \\
\cline { 2 - 8 } & 1 & 2 & 3 & 4 & 5 & 6 \\
\hline \hline 1 & 0.96 & 0.03 & 0.07 & 0.00 & 0.00 & 0.00 \\
\hline 2 & 0.02 & 0.91 & 0.27 & 0.09 & 0.00 & 0.00 \\
\hline 3 & 0.01 & 0.05 & 0.53 & 0.09 & 0.00 & 0.00 \\
\hline 4 & 0.00 & 0.01 & 0.13 & 0.64 & 0.22 & 0.00 \\
\hline 5 & 0.00 & 0.00 & 0.00 & 0.18 & 0.78 & 0.00 \\
\hline 6 & 0.00 & 0.00 & 0.00 & 0.00 & 0.00 & 1.00
\end{tabular}

\section{Classification of Learners by SOM}

Table IV shows the calculated similarity of each types. We count the number of learners in each units of competitive layer of the SOM. The similarity $s_{i j}$ that illustrated in Table IV is calculated by equation (1). $n_{i j}$ means a training data of type $i$ is mapped on a unit that a training data of type $j$ is mapped, too. $S_{i}$ that is illustrated in Table IV means the total number of the training data categorized in type $i$.

$$
s_{i j}=\frac{n_{i j}}{S_{i}}
$$

For example, in the case of a training data of type 1 are mapped on a unit that a training data of type 2 is mapped, too, the similarity $s_{12}$ is calculated by equation (2).

$$
s_{12}=\frac{n_{12}}{S_{1}}=\frac{1}{81}=0.02
$$

In addition, the Neophyte that couldn't get a good score on the online test, is classified by the score of the questions of legal terms without considering their academic skills. Therefore, the Neophyte distributed in pieces. Taken together, we consider that the classification results well represent the relationship of each type.

\section{E. Re-Classification Rules}

In the recent study, we found that unsupervised classification 


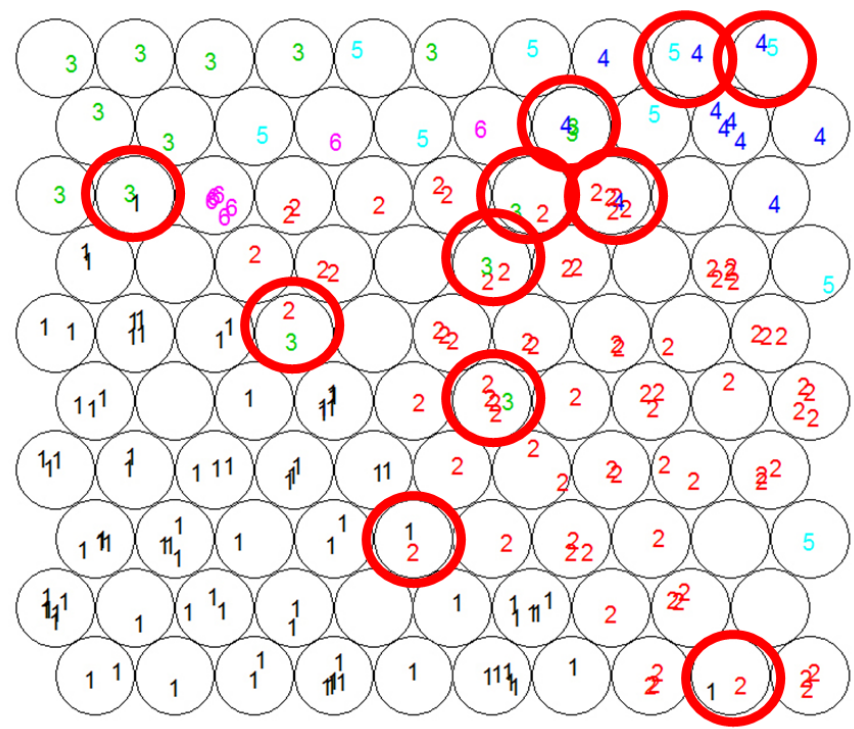

Fig. 2. Distribution of Learners' Comprehension Type Classified by

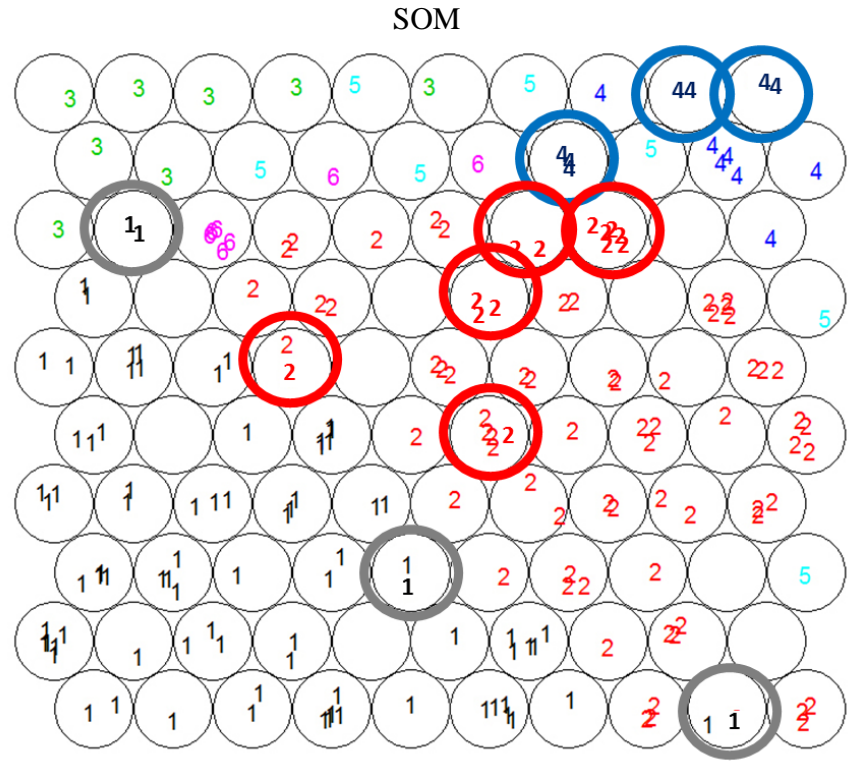

Fig. 3. Distribution of Learners' Comprehension Type Revised by Knowledge-Based Processing

method is useful to rough classification, but knowledge-based processing easily revises misclassification [7]. Therefore, we introduce the teaching knowledge to revise the misclassification.

We describe the re-classification knowledge in IF THEN rules illustrated in Table $\mathrm{V}$. At first, learners who took high scores on average for all skills would be classified as a category Master. Since misclassification occurred in the category Adept or Careless as illustrated in Table IV, we revise their category to Master. Next, the other learners whose lowest skill was Thinking nearly equals to Judgement would be classified as a category Adept. Therefore, we revise them to Adept. Finally, we revise the other misclassification with Apprentice to Apprentice to provide individual guidance conveniently.
TABLE V. RE-CLASSIFICATION RULES

IF ( Mixed Patterns ) --------> THEN ( Revised Category )

\begin{tabular}{l|l}
\hline \hline Master and Others & Master \\
\hline Adept and Others (Exclude Master) & Adept \\
\hline Careless and Apprentice & Apprentice \\
\hline Apprentice and Neophyte & Apprentice
\end{tabular}

\section{RESUlTS AND DisCUSSIONS}

The experiment was proceeded to the learners in an introductory course of on-demand e-Learning at five universities in Japan. Fig. 2 shows the classification results of learners by SOM classifier. The training data of learners is distributed on the competitive map, named as numeric codes illustrated in Table I.

We employed one hundred units on the competitive layer. We used a "kohonen" package for R language. $\mathrm{R}$ is a free software environment for statistical computing and graphics. The units that represent the type of Neophyte are classified in an opposite corner to that of Master, and the type of Apprentice and Careless, too. The Adept is classified nearby the Master. We can read the relationship between the types of learners' comprehension from the map.

We can utilize the classification results to support the learning. For example, the Neophyte that is plotted in the cluster of the Adept, has a characteristic of not good at Thinking. We think it is suitable to recommend the learner learning contents that enhance the Thinking skill.

Fig. 3 and Table VI show the revised distribution of learners' comprehension. The all misclassification illustrated in Table IV TABLE VI. REVISED DATA

\begin{tabular}{r|r|r|r|r|r|r}
\multirow{2}{*}{$\begin{array}{l}\text { Classification } \\
\text { Results of Type } j\end{array}$} & \multicolumn{7}{|c}{ Training Data of Type $i$} \\
\cline { 2 - 8 } & 1 & 2 & 3 & 4 & 5 & 6 \\
\hline \hline 1 & 1.00 & 0.00 & 0.00 & 0.00 & 0.00 & 0.00 \\
\hline 2 & 0.00 & 1.00 & 0.00 & 0.00 & 0.00 & 0.00 \\
\hline 3 & 0.00 & 0.00 & 1.00 & 0.00 & 0.00 & 0.00 \\
\hline 4 & 0.00 & 0.00 & 0.00 & 1.00 & 0.00 & 0.00 \\
\hline 5 & 0.00 & 0.00 & 0.00 & 0.00 & 1.00 & 0.00 \\
\hline 6 & 0.00 & 0.00 & 0.00 & 0.00 & 0.00 & 1.00
\end{tabular}

has been revised, so that we can provide the individual guidance relative to the type of learners' comprehension conveniently. 


Type: Apprentice
Learner who memorized the meaning of the legal terms.
Score of Four Skills:
Mem: 0.51 Jud: 0.51 Thi: 0.35 App: 0.31
Correct Answer's Ratio (\%)
$100 \%$
$80 \%$
$40 \%$
$20 \%$
$0 \%$
Level-Up Question!!
Q: In the case that an applicant for a patent received a notice of reasons for
refusal by an examiner, what measures does the applicant have to choose?
Compare the following descriptions then choose the most inappropriate one.
a: written opinion shall be submitted in writing
b: written appeal for trial shall be submitted in writing
c: written amendment of proceedings shall be submitted in writing
A: b

Fig. 4. Sample Contents for One-on-one Instruction

Fig. 4 shows a sample of the individual guidance for one-on-one instruction. The guidance consists of three contents, namely, Type, Score of Four Skills and Level-Up Question. The Type means a learner's comprehension type and the score illustrated by both values and visuals. The Level-Up Question is shown to support enhancing the learner's skill. In this case, comprehension type of the learner is categorized as Apprentice, and the sample question is about proceedings for a patent applicant. The question needs Thinking skill mainly to be solved.

\section{CONCLUSION}

In this paper, we apply the one-on-one instruction function based on learners' comprehension after revised misclassification by teaching knowledge. Since the proposed method produces compact distribution of learners' comprehension, the teacher would make the one-on-one instruction easily.

\section{ACKNOWLEDGMENT}

This work was supported by JSPS KAKENHI Grant Number 15K00483 and 18K11571.

\section{REFERENCES}

[1] H. Murai and H. Okumura, "Assistance of Understanding by e-Learning," Journal of the educational application of information, vol. 7, no. 1, pp. 31-35, 2004. [published in Japanese]

[2] H. Murai, "Intellectual Property Learning System Supported by SOM," IEICE Technical Report of NLP, vol. 105, no. 547, pp. 113-116, 2006. [published in Japanese]

[3] H. Murai, T. Hayashi, R. Yaegashi, K. Fujimoto and N. Gotoda, "A Study of Classification of Quizzes on Intellectual-Property Education”, Int'l
Journal of Computing, Communications \& Instrumentation Eng. (IJCCIE), vol. 3, no. 1, pp. 123-124, 2016. https://doi.org/10.15242/IJCCIE.AE01160012 http://dx.doi.org/10.15242/IJCCIE.AE01160012

[4] H. Murai, K. Fujimoto, T. Hayashi, N. Gotoda, R. Yaegashi, "Intellectual-Property Learning System Supported by SOM Classifier", Proc. Int. Conf. on Artificial Intelligence Science and Technology, pp.113-118, 2016.

[5] H. Murai, "Similarity of Learners' Understanding Type Classified by SOM on Intellectual-Property Education", Proc. 2016 Int. Conf. on Recent Development in Engineering and Technology (RDET-16), pp.61-62, 2016.

[6] H. Murai and S. Omatu, "Remote Sensing Image Analysis using a Neural Network and Knowledge-Based Processing", International Journal of Remote Sensing, No. 18, pp.811-828, 1997. https://doi.org/10.1080/014311697218773

[7] H. Murai, T. Hayashi, R. Yaegashi, A. Iwaki, and K. Ura, "Development of Gaming App to Support Memorizing Keywords in Law Learning," Technical Report of Japanese Society for Information and Systems in Education, vol. 29, no. 3, pp. 3-6, 2014. [published in Japanese]

[8] H. Murai, "Knowledge-Based Method for Revising Misclassification on Learners' Comprehension", Proc. 6th Int. Conf. on Advances in Engineering and Technology (RTET-2017), pp.18-21, 2017. 